\title{
THE NEXUS BETWEEN TRANSFORMATIONAL LEADERSHIP AND TEAM EFFECTIVENESS: A CONCEPTUAL REVIEW
}

\author{
${ }^{1}$ Dr. Miebaka Dagogo Tamunomiebi and ${ }^{2}$ David, Gabby Okwudiri \\ ${ }^{1}$ Department of Management, Faculty of Management Sciences, Rivers, State University, \\ Nkpolu-Oroworukwo, PMB 5080, Port Harcourt, Nigeria. \\ ${ }^{2}$ Doctoral Candidate Department of Management, Faculty of Management Sciences, Rivers \\ State University, Nkpolu-Oroworukwo, PMB 5080, Port Harcourt, Nigeria.
}

\begin{abstract}
Transformational leaders motivate followers to achieve performance beyond expectations by transforming their attitudes, beliefs, and values as opposed to simply gaining compliance. Transformational leadership was conceptualized as being composed by four independent dimensions, known as the four "I"s : inspirational motivation (the sense of drive that the leader inspires in followers and that produces additional, goal-oriented energy for the group or organization), intellectual stimulation (the boost in creativity in followers that the leader stimulates by encouraging an independent and innovative way of thinking), idealized influence (exemplary behaviour of the leader that generates respect and trust and makes followers proud of their group and organization), and individualized consideration (perception that the leader genuinely cares for followers and their well-being). This paper examines the nexus between transformational leadership and team effectiveness.
\end{abstract}

KEYWORDS: transformational leadership, team effectiveness, idealized influence, inspirational motivation, intellectual stimulation, individualized consideration

\section{INTRODUCTION}

Leadership is the action of equipping and developing followers, as well as providing direction on issues and deployment of resources towards an organization's goals and objectives (Daft, 2015). The performance and sustainable success of organizations rests on the leadership. Daft mentions that there exist different types of leadership, such as visionary, charismatic, transactional, autocratic, and transformational. In transactional leadership, the leader promotes compliance by followers through various tactics such as rewards and punishment. In charismatic leadership, the leader provides guidance through charm and persuasion. For transformational leadership, the leader works with subordinates or followers to identify needed change, creates a vision to guide the change through inspiration, and executing the change in close collaboration with committed members of a team (Bell \& Menu, 2012).

Transformational leaders exhibits the four characteristics of idealized influence, inspiration motivation, intellectual stimulation and individualized consideration (Northouse, 2014). Globally, Matthias and Eline (2012) mention that various studies carried out have demonstrated that transformational leadership is linked to good individual and organizational performance. Organizations, as well as individuals, both have goals and objectives that they exist to pursue in line with their vision and mission. The realization of these goals, and or objectives comes through great effort, which leadership must put into consideration. Transformational leadership greatly affects the performance of an organization by influencing the behavior of subordinates to optimize their performance and outcomes (Yukl \& Van, 2015). Transformational leadership is purpose driven in such manner that goes beyond short-term goals. Bass and Avolio (2006) 
notes that it is an important ingredient in building the confidence and synergy that is required for work-teams to be successful when facing difficult challenges.

Transformational leadership is often associated with progressive change in organizations, as well as enhancement of employee performance and satisfaction (Roach \& Mack, 2014). Leaders, who exhibit transformational style of leadership, offer guidance that spur intellectual curiosity and inspire achievement in their followers. Additionally, by being attentive to individual needs and development, transformational leaders empower teams to develop skills in leadership, which subsequently improves their performance and outcomes. Bass and Riggio (2010) pointed out that, the transformative leadership is a powerful model for a wide scope of fields and societies. Transformational leaders influence practices associated with proactive initiative in driving change that can enhance achievement of organizational goals. Realization of organizational goals and sustained performance improvement is the ultimate desire of every leader. The goals that transformational leaders communicate vary in metric terms, and are realized through application of multiple strategic approaches (Hamidifar, 2013).

\section{LITERATURE REVIEW}

\section{Idealized Influence}

Idealized influence is the behavior of a leader who inspires trust, admiration, and respect among a team to the extent that members emulate him/her. In general, it entails leading by example in all aspects that influence and shape opinions of followers. A transformational leader is expected to exhibit idealized influence (Lim \& Ployhart, 2014). The bottom-line of idealized influence as an exhibition of transformational leadership is leading by example in all aspects that influence or shape opinions of followers. These may not be limited to public manifestations only, but private action as well (Yukl, 2010). This is because what and how a leader exists in the private space, saliently impacts his leadership influence in general, which can always be observed on how the followers respond. Besides, it is noteworthy that a leader's stability in private space is directly related to his leadership effectiveness in the public arena, particularly for transformational leadership (Conger, 2014).

Idealized influence is the behavior that is reflected by leaders showing charismatic personality. It describes the degree in which leaders are perceived as an inspiring role model and most often such leaders exhibit excellent behavior and might sacrifice their own needs to improve the objectives of their workgroup (Moss \& Ritossa, 2007). Using idealized influence, transformational leaders act in a way that allows them to serve as role models to their subordinates. Bass and Riggio (2006) noted that transformational leaders are admired, respected, and trusted. Their subordinates identify them with charismatic personality and attracted to emulate them. Besides, these leaders are endowed by their followers as having extraordinary capabilities, persistence, and determination.

\section{Inspirational Motivation}

Inspirational motivation is concerned with the creation of a vision, developing clear and plausible strategies for attaining the vision and mobilizing commitment to that vision through communicating the vision to followers in a clear and plausible way (Walumbwa and Lawler, 2013). This is theorized to motivate employees to work together in accomplishing a common goal to meet or go beyond the expected targets or generally termed as extra role performance 
(Uzonna, 2013). The items that were investigated under inspirational motivation were: communication, teamwork, and motivation.

Inspiration motivation is the art of sharing a compelling vision or a goal, constantly motivating team members, boosting confidence, and making assurances despite imminent barriers faced. Transformational leaders exhibit this attribute (Ladd \& Marshal, 2014). A transformational leader is expected to exhibit inspiration motivation (Koys, 2014). In this study, it is the influence of inspiration motivation on the performance of judicial staff that was being measured. The measurements were considered as working with teams, communicating using appealing words and symbols, and job autonomy. Inspiration motivation has to do with coherently putting forth organizational goals and objectives, and is an attribute that is associated with transformational leaders. Research has demonstrated that clarity of organizational goals and expectations has a direct contribution on how every person in the team performs. Equally attributable to inspiration motivation is the insatiable push by the leader to ensure that there exists mutual consensus within the team members (Kelchner, 2013). Leaders, who are transformational, are astute at articulating compelling visions for the future, in such a manner that enhance ownership at an emotional level among the team members, making them improve in what they do (Manteklow, 2011).

The extent of inspiring and stirring up followers into progressive and productive action is not a question for inspirational motivation leaders, it is the hallmark of their leadership being. That puts a demand on them to continuously learn and employ tactics that are fresh in triggering and sustaining cooperation and team spirit at the place of work. The result of such action from the leader will be experienced everywhere, ranging from fostering inter-team collaboration, to a culture of collective responsibility (Bass, 2012).

By considering Sundi (2013), the dimensions of inspirational motivation indicate that respondents have enthusiasm to carry out tasks because the leader can arouse the aspirations of subordinates, and subordinates are also able to advance team spirit in all tasks at hand. Key to organizational performance is ensuring that trust and satisfaction among employees is entrenched through practices such as the freedom to make choices and decisions on how tasks can be accomplished faster. This can be looked at further from Rawung, Wuryaningrat and Elvinita (2015) perspective when they say that leaders, who exhibit inspirational motivation, greatly excel at establishing a culture of trust among employees, by giving them the space to independently think through on the best approaches applicable in every unique work situation. Accordingly, they argue that inspirational motivation sets the basis for sharing knowledge, which is key at enhancing job autonomy and general performance of the organization. Given that the judiciary is a vital arm in national governance, it is for the same reasons, that a study to understand what inspirational motivation can have on performance of judicial staff is important.

Managers have more influence, than perhaps they realize, on their employees' engagement, optimism, and performance, and can consciously use this influence to benefit these employees and the organization as a whole (Greenberg \& Arakawa, 2006). The capacity to accurately evaluate process and outcome performance issues that characterise optimistic individuals is likely to drive resilient behaviours, such as utilisation of error as a springboard for learning and for fine-tuning performance (Nguyen, Kuntz, Naswall \& Malinen, 2016) 
Empirical research linking optimism to commitment to change, ability to cope with changing work environments and positive workplace behaviours (Kool \& Dierendonck, 2012; Youssef \& Luthans, 2007) further suggests that higher levels of optimism may be related to resilient behaviours, which encompass change adaptability. The importance of manager optimism is supported by Popper, Amit, Gal, Mishkal-Sinai, and Lisak (2004), who observe that optimism is one of three psychological capacities essential for leadership. Similarly, Humphrey (2002) argues that the emotional displays of leaders have a larger impact on employees than the content of their messages.

\section{Intellectual Stimulation}

Intellectual stimulation is a character of leaders who inspire people's creativity and innovativeness, encouraging them to question norms and seek for new approaches and solutions to problems (Hall \& Keilitz, 2012). A transformational leader is expected to exhibit intellectual stimulation (Bass \& Avolio, 2006). Key aspect of intellectual stimulation is promoting innovation and creativity by the leader, so that team members do not settle for conventional norms and known ways of tackling issues (Elkins \& Keller, 2013). Geyer and Steyrer (2010) further argue that through intellectual stimulation, new frameworks are established that enable people to constructively dismantle old assumptions and essentially develop more innovative methods and approaches.

Through intellectual stimulation, transformational leaders are able to show their followers new ways of looking at problems. Such leaders encourage their followers to use non-traditional thinking to deal with traditional problems and they give ear to subordinates' ideas even if different from theirs. A recent study conducted in Nigeria stated that intellectual stimulation provokes followers to think new methods and means in an innovative ways by getting them involved in the process of decision-making as well as problem solving that impact on their social, economic, environmental and political wellbeing (Nwagbara, 2010). Intellectual simulation had a statistically significant positive correlation with effectiveness and satisfaction in the quantitative study. According to the study encouraging and expecting followers to challenge their own old ways of doing things were key ingredients that help to keep on changing. Leaders who are intellectually stimulating see the advantages of creating unity through diversity. By bringing together and integrating a diverse range of perspectives, they are able to create genuinely new ideas and initiatives. The goal of intellectual stimulation is to continuously generate the highest levels of creativity from the subordinates (Avolio, 2005).

Leaders who are transformational, challenges followers to collectively participate in finding new solutions to work-related problems, especially where performance improvement is an imperative. These leaders go further to establish an organizational atmosphere that makes participation, both as an individual and collectively as teams, the norm. Such leaders intellectually stimulate followers to question common assumptions and status quo, besides finding innovative and creative ways of solving challenges (Smothers, Doleh, Celuch, Peluchette \& Valadares, 2016). Workplace participation and interaction is not only a medium for discussion and sharing of responsibilities, but also, a platform for productive and continuous strategic communications, leading to performance improvement (Bhatti \& Qureshi, 2011). An organization can be formulating a direction for achieving certain goals through articulation of ideas. Bell and Menguc (2012) opines that vision plays the role of pointing the direction an institution intends to take. It is the responsibility of the transformational leader not only to 
Print ISSN: 2053-4019(Print),

Online ISSN: 2053-4027(Online)

stimulate the follower's intellect by painting a directional picture, but also the methodology for execution.

\section{Individualized Consideration}

Individualized consideration is the quality of a leader who extends personalised attention to the followers, in which case, he or she plays both coaching and mentoring roles. It entails extending empathy and support, keeping communication with followers, creating a culture of respect, and celebrating the contribution of others (Bass \& Riggio, 2006). A transformational leader is expected to exhibit individualized consideration (Bass \& Avolio, 2006). Individualized consideration entails responding to people's unique needs by including everybody in the process of a transformational initiative (Conger, 2014). These leaders also are effective at delegating duties, which does facilitate efficiency and hence improvement in performance. Delegation is the tasking of one or more important errands or obligations, either operational or administrative in nature, to subordinates (Conger, 2014). Sometimes those in leadership underestimate the power in delegation. In the hindsight, delegation when practiced objectively is a sure motivating tool at the place of work, helping to create energized and high performing teams (Zheng, Yang \& Mclean, 2010).

One of the key ways on how transformational leaders work, is that they deal with their team members as individuals. This is because, they appreciate that followers are unique and so, have specific needs and diverse knowledge. This attribute makes them to be good at maximizing the benefits that accrue from workplace diversity. On the same note, when it comes to recognition, they consider people on a case by case basis. Thus, they are known for establishing organizations that are keen on the continued growth through harnessing the power of workplace diversity. This is realized, argues Babbington (2015), when a culture that creates opportunities for learning is entrenched, yet without forgetting the reality that there will always be differences arising from individuals behaviors. Transformational leaders also strive to ensure that the working conditions in an organization are acceptable to the majority, if not all. They strive for acceptable working conditions because they are aware that challenging work, absence of wellbeing, multifaceted nature of monotony and lack of self-governance in the occupation, make it difficult for workers to accept working conditions (Ornels \& Kleiner, 2013).

\section{Transformational Leadership and Team Effectiveness}

By clarifying the goals and purpose of task at hand, a leader increases the teams' performance (West, Borrill, Jeremy, Brodbeck, Shapiro \& Haward, 2003). Different researchers have argued that the various characteristics of leadership styles affect the performance of the team. According to Bish and Kabanoff (2014) aligning the perceptions a manager has on good performance, the willingness of employees to be self-directed and the leaders' willingness to lead influences team performance. Geoghegan and Dulewicz (2008) further note leadership competence of a project manager leads to its success.

Transformational leadership therefore promotes efficiency and effectiveness of the team by clarifying goals and accepting diverse views of the team members (Chi \& Huang, 2014). The aim is to encourage individuals to rise above the status quo in order to improve group innovation and adaptability. They additionally acquire other team skills to enable them resolve conflicts, communicate effectively and uphold team cohesion (Dionne, Yammarino, 
Atwater, \& Spangler, 2004). This is a big boost to developing good personal relationships as well as achievement of good performance (Geoghegan \& Dulewicz, 2008).

A leader, who promotes confidence in achievement and execution of goals and tasks, speaks optimistically about the future and provides an exciting image of organizational change, exhibits idealized, inspirationally motivating behaviors (Bass \& Avolio, 1994). Moreover, these behaviors may be instrumental in building pride in being associated with the leader (Atwater \& Bass, 1994), and commitment to the leader (Arnold et al., 2001), which can in turn, provide a commonality for members of the team to embrace. This shared pride and commitment to the leader has the potential to lead to increased cohesion, as members view themselves as privileged to be associated with the transformational leader (Atwater \& Bass, 1994).

Increased listening, prompt feedback and openness to suggestions within the team is necessary for effective performance (Dyer, 1995; Stevens and Campion, 1994). It is important to state that individualized consideration encompasses attentive listening, consideration of individuals as having different needs, abilities and aspirations, and time spent in coaching and teaching (Bass, 1990). The individually considerate leader is responsible for constructing a one-to-one relationship with each team member, listening to concerns and addressing individual needs (Bass, 1994; Yammarino, Dubinsky \& Spangler, 1998). As such, the transformational leadership dimension of individualized consideration may be an appropriate precursor to effective team communication.

These individually considerate behaviors may serve to empower team members and open and extend lines of communication between the leader and each member of the team. Although there is some empirical evidence that general transformational leadership is indirectly related to empowerment (Kark, Shamir \& Chen, 2003). These actions may serve to create a supportive, empowered team environment (Spreitzer, 1995).

Chen and Tjosvold (2002), argued that a team benefits from conflict when that team develops a quality solution and strengthens relationships. Thus, effective conflict management can lead to better team performance (Stevens \& Campion, 1994), as a team is not dragged down by infighting and indecision. Research suggests that conflict, particularly cognitive or taskoriented conflict, can be an important antecedent to team effectiveness and performance (Amason, 1996). Moderate levels of task conflict are viewed as functional conflict, or conflict which supports the goals of the group/team and improves the group's/team's performance (Jehn, 1997). Jehn (1995) found that norms open to and tolerant of disagreement were positively related to task conflict dimension. As such, developing a team's attitudes and norms toward the functional benefit of team conflict may improve its ability to constructively manage the conflict.

Intellectual stimulation can create an environment, where questioning assumptions and inventing new uses for old processes (Bass, 1985, 1990) are considered a healthy form of conflict. Using intellectually stimulating behavior, such as seeking differing perspectives, suggesting new ways of how to look at problems and encouraging non-traditional thinking, may promote functional, task-oriented conflict within the team. A leader's use of intellectual stimulation exhibits his/her belief that when teams promote and manage task conflict, the 
Print ISSN: 2053-4019(Print),

Online ISSN: 2053-4027(Online)

resulting innovation can lead to better team performance and decision-making (Bass \& Avolio, 1994).

Team cohesion is critical for effective team performance (Swezey \& Salas, 1992; Weaver, Bowers, Salas \&Cannon-Bowers, 1997), and as such, is a key area that could be addressed when investigating transformational leadership's potential relationship with team performance. Transformational leadership has been empirically linked to cohesion in the past.

Evidence of a direct effect of idealized influence/inspirational motivation on individual performance exists (Bass and Avolio, 1994; Densten, 2002). Idealized influence/inspirational motivation impacts cohesion through visioning behaviors involving rapport building and empathetic language. Although previous empirical findings displaying both direct effects of transformational leadership (general factor) on performance (Avolio \& Yammarino, 2002) and mediated effects through cohesion (Bass et al., 2003; Sosik et al., 1997).

\section{Empirical Reviews}

Sookaneknun and Ussahawanitchakit (2012) explored the relationships among transformational leadership (idealized influence, inspirational motivation, intellectual stimulation, and individualized consideration), organizational innovation capability and firm performance with market culture as a moderator in the context of cosmetic industries in Thailand. The study revealed that of the four dimensions of transformational leadership only idealized influence had an effect on organizational innovation capability. However, when all four dimensions were integrated as transformational leadership, it had a positive influence on organizational innovation capability. Secondly, organizational innovation capability had a positive effect on firm performance.

According to Odumeru and Ifeanyi (2013), transformational leadership enhances the motivation, morale, and performance of followers through a variety of mechanisms. These include connecting the follower's sense of identity and self to the project and the collective identity of the organization; being a role model for followers that inspires them and makes them interested; challenging followers to take greater ownership for their work, and understanding the strengths and weaknesses of followers, so the leader can align followers with tasks that enhance their performance. They further note that transformational leaders were evaluated as more effective, higher performers, more promotable than their transactional counterparts, and more interpersonally sensitive. They also indicate that transformational leadership is strongly correlated with employee work outcomes including lower turnover rates, higher level of productivity, employee satisfaction, creativity, goal attainment and follower well-being.

\section{CONCLUSION}

Transformational leadership is a leadership style that raises followers' awareness of the importance of task outcomes, activates higher-order needs, and motivates followers to transcend self-interests for the sake of the organization (Yukl, 2013). Transformational leadership is generally considered helpful for team functioning. Transformational leadership has been linked to team functioning and team performance (Wang, Oh, Courtright, \& Colbert, 
Print ISSN: 2053-4019(Print),

Online ISSN: 2053-4027(Online)

2011). In conclusion, transformational leadership has been found to positively impacts team performance (Zhang, Li, Ullrich, \& Dick, 2015).

\section{REFERENCES}

Amason, A.C. (1996). Distinguishing the effects of functional and dysfunctional conflict on strategic decision making: Resolving a paradox for top management team. Academy of Management Journal, 39, 123-48.

Atwater, D. \& Bass, B.M. (1994). Transformational leadership in teams, in Bass, B. and Avolio, B. (Eds), Improving organizational effectiveness through transformational leadership. Thousand Oaks, CA, Sage, 48-83.

Avolio, B. J (2005). Leadership development in balance. New Jersey: Lawrence Erlbaum Associates Inc.

Babbington, K. (2015). Why elephants gallop: Assessing and predicting organizational performance in federal agencies. Journal of Public Administration Research and Theory, 10 (2), 685-711.

Bass \& Riggio, (2010). Leading organizations: Perspectives for a New Era edited by Gill Robinson Hickman, Los Angeles: Sage Publications.

Bass, B. M. \& Avolio, B. J. (2006). Transformational leadership and organizational culture, Public Administration Quarterly, 12, 113-121.

Bass, B. M. (2012). The ethics of transformational leadership, KLSP: Transformational Leadership. Working Papers.

Bass, B., \& Riggio, R. (2006). Transformational leadership. New Jersey: Lawrence Erlbaum Associates, Inc.

Bass, B.M. (1990). Bass and Stogdill's Handbook of Leadership. Thousand Oaks, CA: Sage.

Bass, B.M. (1994). Transformational leadership and team and organizational decision making", in Bass, B. and Avolio, B. (Eds), improving organizational effectiveness through transformational leadership. Thousand Oaks, CA: Sage, 104-20.

Bell, Z., \& Menguc M. (2012). Transformational leadership in an acquisition: A field study of employees. The Leadership Quarterly, 18, 49-68.

Bhatti, Q., \& Qureshi C. (2011).Introducing a grass-roots mode of leadership. Strategies \& Leadership, 27(6), 18-20.

Bono, J. E., \& Judge, T. A. (2004). Personality and transformational and transactional leadership: A meta-analysis. Journal of Applied Psychology, 89(5), 901-910.

Chen, G. \& Tjosvold, D. (2002). Conflict management and team effectiveness in China: the mediating role of justice. Asia Pacific Journal of Management, 19, 557-72.

Chi, N.-W., \& Huang, J.-C. (2014). Mechanisms linking transformational leadership and team performance: The mediating roles of team goal orientation and group affective tone. Group \& Organization Management, 39(1), 1-26.

Conger, J. A. (2014). Overview charismatic and transformational leadership: taking stock of the present and future (part 1). Leadership quarterly, 10 (2), 121-127.

Daft, R. (2015). The leadership experience. Toronto: Southwestern

Densten, I.L. (2002). Clarifying inspirational motivation and its relationship to extra effort. Leadership and Organization Development Journal, 23(1/2), 40-4.

Dionne, S. D., Yammarino, F. J., Atwater, L. E., \& Spangler, W. D. (2004). Transformational leadership and team performance. Journal of Organizational Change Management, 17, 177-193. 
Dyer, W.G. (1995). Team building: current issues and new alternatives, 3rd ed., AddisonWesley Publishing Company, New York, NY.

Elkins, M., \& Keller. (2013). Leadership models, methods, and applications. In I. B. Weiner (Series Ed.) \& W. C. Borman, D. R. Ilgen, \& R. Klimoski (Vol. Eds.), Handbook of psychology, Vol. 12: Industrial and organizational psychology (pp. 277- 307). Hoboken, NJ: Wiley.

Geoghegan, L., \& Dulewicz, V. (2008). Do project managers' leadership competencies contribute to project success? Project Management Journal, 39(4), 58-67.

Geyer, T., \& Steyrer, N. (2010).An exploration of perspective taking as an antecedent of transformational behavior. Leadership and Organisational Behavior Journal, 32(8), 807-816.

Greenberg, M. H. \& Arakawa, D. (2006). Optimistic Managers \& Their Influence on Productivity \& Employee Engagement in a Technology Organization. Master of Applied Positive Psychology,Capstone Projects. 3.

Hamidifar, F. (2013). A study of the relationship between leadership styles and employee job satisfaction at Islamic Azad University branches in Tehran, Iran. AU-GSB- eJournal, $1-13$.

Humphrey, R. H. (2002). The Many faces of emotional leadership. The Leadership Quarterly, 13(5), 493-504.

Jehn, K.A. (1995). A multi-method examination of the benefits and detriments of intragroup conflict. Administrative Science Quarterly, Vol. 40, pp. 256-82.

Jehn, K.A. (1997). A qualitative analysis of conflict type and dimensions in organizational groups. Administrative Science Quarterly, 42, 530-57.

Kark, R., Shamir, B., \& Chen, G. (2003). The two faces of transformational leadership: empowerment and dependency. Journal of Applied Psychology, 88(2), 246-55.

Kelchner, E. (2013). Creativity and innovation: The leadership dynamics. Journal of Strategic Leadership, 1(1), 2008, 39-45.

Kool, M., \& Van Dierendonck, D. (2012). Servant leadership and commitment to change, the mediating role of justice and optimism. Journal of Organizational change Management, 25(3), 422-433

Koys, D. J. (2014). Inductive measures of psychological climate. Human Relations, 44(3), 265285.

Ladd, Y., \& Marshall, M. (2014). Transformational leadership and dimensions of creativity: Motivating idea generation in computer-mediated groups. Creativity Research Journal, 11(2), 111-121.

Lim, S., \& Ployhart, J. (2014). A short measure of transformational leadership. Journal of Business and Psychology, 14 (3), 389-405.

Manteklow, J. (2011). Forming, storming, norming, and performing. Retrieved from: http://www.mindtools.com/pages/article/newLDR_86.htm

Matthias, A., \& Eline, O. (2012).Embracing transformational leadership: Team values and the impact of leader behavior on team performance. Journal of Applied Psychology, 92(4), $1020-1030$

Nguyen, Q., Kuntz, J. R., Naswall, K., \& Malinen, S. (2016). Employee resilience and leadership styles: The moderating role of proactive personality and optimism. New Zealand Journal of Psychology, 46(2).

Northouse, P. G. (2014). Leadership: Theory and practice (7th edn). London, UK: Sage Publications. 
Nwagbara, U. (2010). Towards a paradigm shift in the Niger Delta: Transformational leadership change in the era of post amnesty deal. Journal of Sustainable Development in Africa, 12(3).

Odumeru, J. A., \&Ifeanyi, G. O. (2013).Transformational vs. transactional leadership theories: evidence in literature. International Review of Management and Business Research, 2(2), 355-361.

Ornels, P., \& Kleiner, U. (2013).Achieving and sustaining school effectiveness: A five year study of change in elementary schools. Paper presented at the Annual Meeting of the American Educational Research Association, Boston, MA.

Popper, M., Amit, K., Gal, R., Mishkal-Sinai, M., \& Lisak, A. (2004). The Capacity to Lead: Major Psychological Differences Between Leaders and Nonleaders. Military Psychology, 16(4), 245, 19.

Smothers, D., Celuch, P., \& Valadares, K. (2016).The influence of financial participation and participation in decision-making on employee job attitudes. International Journal of Human Resource Management, 15, 3, 587-616.

Sookaneknun, S., \& Ussahawanitchakit, P. (2012). Transformational leadership, organizational innovation capability, and firm performance of cosmetic businesses in Thailand. Journal of International Business and Economics, 12(4), 77-91.

Spreitzer, G.M. (1995). Psychological empowerment in the workplace: Dimensions, measurement and validation. Academy of Management Journal, 39, 483-504.

Stevens, M.J. \& Campion, M.A. (1994). The knowledge, skill and ability requirements for teamwork: implications for human resource management. Journal of Management, 20, 503-530.

Sundi, K. (2013). Effect of transformational leadership and transactional leadership on employee performance of Konawe Education Department at Southeast Sulawesi. International Journal of Business and Management Invention

Swezey, R.W., \& Salas, E. (1992). Guidelines for use in team-training development, in Swezey, R.W. and Salas, E. (Eds), teams: their training and performance. Ablex Publishing Corporation, Westport, CT, pp. 219-45.

Uzonna, U. R. (2013). Impact of motivation on employees' performance: A case study of Credit West Bank Cyprus. Journal of Economics and International Finance, 5(5), 199.

Wang, G., Oh, I. -S., Courtright, S. H., \& Colbert, A. E. (2011). Transformational leadership and performance across criteria and levels: A meta-analytic review of 25 years of research. Group \& Organization Management, 36, 223-270

Weaver, J.L., Bowers, C.A., Salas, E. \& Cannon-Bowers, J.A. (1997). Motivation in work teams, in Beyerlein, M., Johnson, D. and Beyerlein, S. (Eds), Advances in Interdisciplinary Studies of Work Teams. Greenwich, CT: JAI Press, Inc. 167-91.

West, M., Borrill, C. S., Jeremy, D. F., Brodbeck , F., Shapiro, D. A., \& Haward, B. (2003). Leadership clarity and team innovation in health care. The Leadership Quarterly, 14, 393-410.

Walumbwa, F. O. \& Lawler, J. J. (2013). Building effective organizations: Transformational leadership, collectivist orientation, work-related attitudes, and withdrawal behaviors in three emerging economies. International Journal of Human Resource Management, 14(7): 1083-1101.

Yammarino, F.J., Dubinsky, A.J. \& Spangler, W.D. (1998). Transformational leadership: individual, dyad, and group levels of analysis. Leadership Quarterly, 9, 27-54. 
Yukl, G. \& Van F., (2015). An evaluation of the conceptual weaknesses in transformational and charismatic leadership theories. Leadership Quarterly, 10(2), 285-305.

Yukl, G. (2010). Leadership in Organizations, 7th edition. Prentice Hall

Yukl, G. A. (2013). Leadership in organizations (8th ed.). Boston, MA: Pearson

Zhang, X. Z., Li, L.N., Ullrich, J.U., \& Dick, R.D. (2015). Getting everyone on board the effect of differentiated transformational leadership by CEOs on top management team effectiveness and leader-rated firm performance. Journal of Management, 41(7), 18981933.

Zheng, W., Yang, H., \& Mclean, C. L. (2010). Consideration for future consequences as an antecedent of transformational leadership behavior: The moderating effects of perceived dynamic work environment. The Leadership Quarterly, 25, 329-343. 